\title{
Odontodisplasia Regional: relato de caso em criança de 5 anos
}

\author{
Regional Odontodysplasia: a case report in a 5-year-old child
}

\author{
Ángel Terrero-Pérez ${ }^{1, a}$, Mariela Peralta-Mamani ${ }^{1, a}$, Alberto Consolaro ${ }^{2, b}$, Ana Lúcia Alvares Capelozza ${ }^{1, b}$. \\ RESUMO
}

A odontodisplasia regional é uma anomalia dentária, pouco comum, não hereditária e com uma etiologia ainda desconhecida. Os tecidos afetados são o esmalte e a dentina, são acometidos nos dentes decíduos e, as vezes na dentição permanente de um mesmo indivíduo. Esta lesão pode ser confundida com outras lesões como por exemplo o odontoma ou dentes com outro tipo de anomalia. O objetivo é relatar um caso de odontodisplasia regional na dentição decídua e permanente de uma criança, assim como apresentar as diferentes ferramentas diagnósticas. Os dentes acometidos mostravam-se ao exame clínico, como dentes hipoplásicos com coloração amarelo amarronzado. Uma radiografia panorâmica e radiografias periapicais, assim como uma biopsia excisional, foram essenciais para obter um diagnóstico correto, e assim poder oferecer uma adequada conduta para a preservação e previsibilidade dos diferentes tipos de tratamentos reabilitadores odontológicos que essa criança poderia ter nos próximos anos até a idade adulta.

Palavras-Chave: Odontodisplasia, anormalidades dentárias, patologia bucal, diagnóstico por imagem, estomatologia.

\section{SUMMARY}

Regional odontodysplasia is an uncommon dental anomaly that is not hereditary and has a still unknown etiology. The affected tissues are enamel and dentin, the primary teeth are affected, and sometimes in the permanent dentition of the same individual. This lesion may be confused with other lesions such as odontoma or teeth with another type of anomaly. The objective is to report a case of regional odontodysplasia in the deciduous and permanent dentition of a child, as well as to present the different diagnostic tools. The affected teeth showed clinical examination, such as hypoplastic teeth with a yellow-brown coloration. A panoramic radiograph and periapical radiographs, as well as an excisional biopsy, were essential to obtain a correct diagnosis, so as to be able to offer an adequate conduct for the preservation and predictability of the different types of dental rehabilitation treatments that this child could have in the years to come adulthood.

Keywords: Odontodysplasia, tooth abnormalities, oral pathology, diagnostic imaging, oral medicine.

Departamento de Estomatologia, Faculdade de Odontologia de Bauru, Universidade de São Paulo. Bauru, SP, Brasil.

Departamento de Patologia, Faculdade de Odontologia de Bauru, Universidade de São Paulo. Bauru, SP, Brasil.

DDS, MSc, Estudante de PhD.

DDS, MSc, PhD, Professor Titular. 


\section{INTRODUÇ̃̃̃O}

A Odontodisplasia Regional (OR) é uma anomalia de desenvolvimento e estrutural que acontece no tecido embrionário mesenquimal e epitelial, afetando os tecidos de esmalte e dentina, assim como a morfologia da polpa. Essa alteração foi divulgada por Hitchin no ano de 1934, no entanto, em 1963 o termo de Odontodisplasia foi adotado para reconhecer e definir o distúrbio. Em 1970, Pindborg adicionou a palavra Regional e assim esta anomalia começou a ser chamada como Odontodisplasia Regional (1-3). Sendo assim, quando esta anomalia afeta um dos quadrantes dos maxilares é denominado de OR. A prevalência da OR resulta ser baixa, com menos de 200 casos relatados na literatura, e o sexo mais acometido é o feminino (4). Apresenta-se frequentemente nos incisivos e caninos superiores como os principais dentes envolvidos, e menos casos acometidos nos dentes inferiores (5).

A etiologia da $\mathrm{OR}$, ainda não é conhecida mas, algumas hipóteses são relatadas como possíveis causas, como por exemplo a condição nutricional, trauma no local, doença sistêmica, alteração metabólica, febre, incompatibilidade do fator Rhesus (Rh), radioterapia e distúrbios na irrigação sanguínea no local ou até mesmo alterações vasculares no próprio germe dental. Por outro lado, a herança não é relatada na literatura como um fator para sua manifestação em mais membros da família (5-8).

O diagnóstico deverá ser tanto clínico quanto radiográfico, para avaliar a extensão da região acometida e fornecer o tratamento adequado segundo a idade do paciente. $\mathrm{O}$ pico da idade em que a lesão é mais diagnosticada são de 2 a 4 anos para dentes decíduos e 7 a 11 anos para os dentes permanentes. Em alguns casos o rango de idade para o diagnóstico aumenta até os 27 anos (5, 9-12). Em muitos casos, os dentes afetados não erupcionam e podem apresentar alterações de forma na coroa, apresentando menor tamanho, com superfícies rugosas, irregulares, cor amarelada ou acastanhada. Assim, devido a essas características ao longo do tempo podem apresentar cárie e lesões periapicais, tendo como consequência a necrose pulpar (12). Radiograficamente, o esmalte e a dentina são finos, não existe um contraste entre eles e possuem uma câmara pulpar aumentada, raízes curtas são presentes e os ápices podem estar em desenvolvimento, o que resulta em aparência difusa dando esse aspecto de "dente fantasma" (12).
Este trabalho tem como objetivo apresentar um caso de OR na dentição decídua e permanente de uma criança, assim como apresentar as diferentes ferramentas diagnósticas.

\section{Relato de caso}

Menino melanoderma, 5 anos de idade, acompanhado por sua mãe à clínica de Estomatologia e Radiologia odontológica da Faculdade de Odontologia de Bauru da Universidade de São Paulo (FOB-USP), com uma queixa principal declarada pela progenitora que "O dente não se desenvolveu". No exame físico extraoral, paciente apresentava baixa estatura, baixo peso corporal correspondente a sua idade e presença de linfonodos submandibulares do lado esquerdo aumentados. Ao exame físico intraoral, foi observado que todos os dentes do terceiro quadrante apresentavam aumento gengival, se encontravam em infraoclusão comparado aos dentes do quadrante oposto, além disso, as coroas dos dentes 71 ao 75 apresentavam uma coloração amarelo amarronzado indicando uma anomalia hipoplasiante, os dentes $74 \mathrm{e}$ 75 apresentavam-se com cárie e abcesso periodontal (Figura 1), levando a uma halitose leve. Devido as características clínicas desses dentes solicitou-se exames de imagem. A radiografia panorâmica e periapicais (Figuras 2 e 3), mostraram que os dentes 71 a 75 possuíam a câmera pulpar e canais pulpares extensos, as raízes curtas e limites imprecisos, do mesmo modo, os germes dos dentes permanentes 31 , 32, 33, 34 e 35 também apresentavam-se afetados com as mesmas características radiográficas, compatível com tecido hipomineralizado e

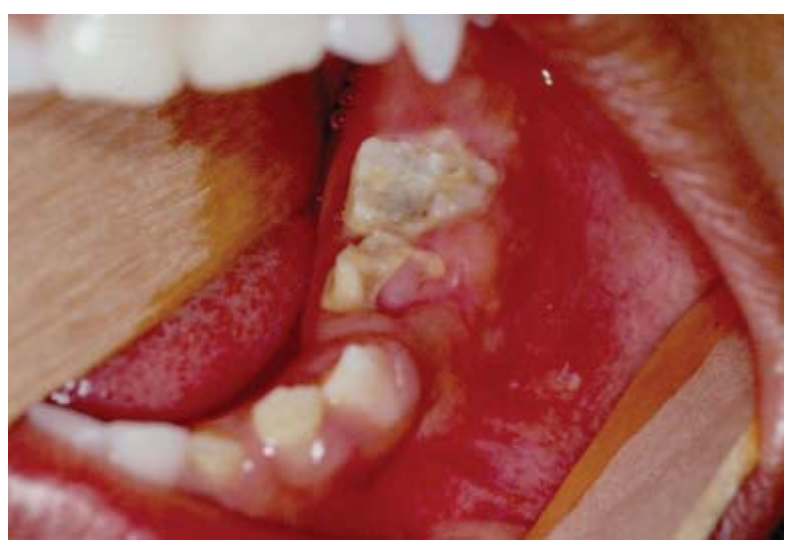

Figura 1. Características clínicas, observamos os dentes decíduos de 71 a 75 com alteração de cor amarelo ou acastanhado, como consequência do esmalte hipomineralizado e hipoplásico. Além disso, os dentes 74 e 75 observam-se com cáries na face oclusal, abcesso periodontal e presença de aumento gengival. 


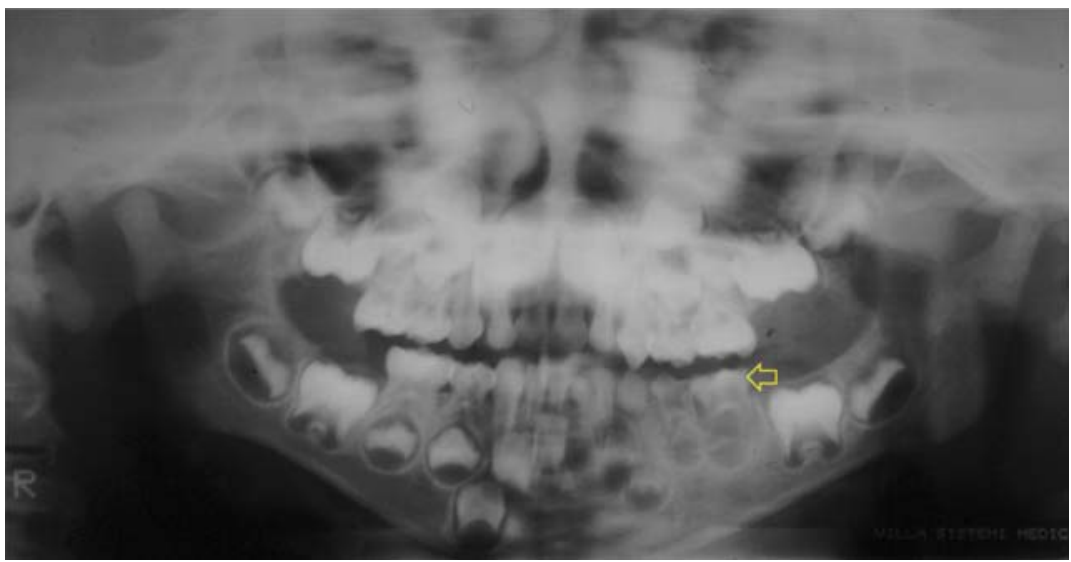

Figura 2. Radiografia panorâmica, na seta amarela, observa-se a porção do terceiro quadrante envolvida, a reduzida mineralização (hipoplasia) do esmalte e dentina nos dentes decíduos de 71 a 75, assim como também os germes dos dentes permanentes 31 a 35 quando comparado ao quadrante oposto, compatível com Odontodisplasia Regional. O dente 36 em irrupção e o germe do 37 encontram-se com seus tecidos dentro dos padrões de normalidade.

Figura 3. Radiografias periapicais. (A) Revelam os dentes decíduos de 75 a 71 e os germes dentários de 31, 32, 33 e 34 parcialmente observados, estão comprometidos e afetados, apresentando características radiográficas de Odontodisplasia regional. (B) Os dentes 74 e 75 encontram-se hipomineralizados e hipoplásicos, com câmaras e canais pulpares amplos, raízes curtas. O dente 75 observa-se uma imagem radiolúcida no periápice compatível com rarefação circunscrita. Igualmente, os germes 34 e 35 apresentam-se também afetados no desenvolvimento. No entanto, o germe do dente 36

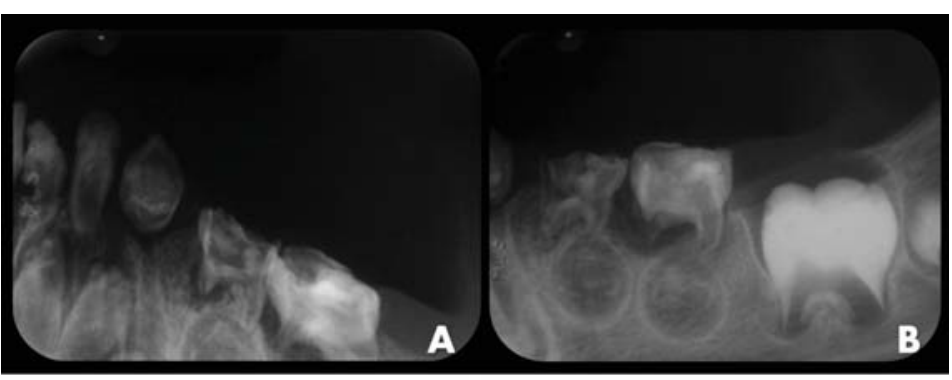
mostra-se em erupção e sem alterações na densidade mineral do esmalte e dentina.

hipoplásico de esmalte e dentina. Além disso, observou-se nas coroas dos dentes 74 e 75 extensas áreas radiolúcidas compatíveis com cárie, no entanto, foi difícil determinar radiograficamente os limites da lesão cariosa, devido à alteração nas estruturas dentarias, pela presença de tecido desorganizado e hipoplásico. Devido às extensas caries nesses dentes com comprometimento pulpar, a conduta foi realizar a exodontia e as peças foram enviadas a exame histopatológico. $\mathrm{O}$ resultado histopatológico mostrou nos dentes, extensas áreas de reabsorção, formação de dentina displásica e interglobular. No tecido pulpar, observou-se numerosos nódulos pulpares, necrose pulpar e colônias bacterianas, nos tecidos periodontais apresentavam, restos epiteliais de Malassez e cementículos. As áreas de reabsorção observadas encontraram-se ora ativas, ora paralisadas, ora reparadas (Figura 4). Assim, de acordo com as características clínicas, radiográficas e histopatológicas, o diagnóstico foi de Odontodisplasia regional. A criança, foi encaminhada para o setor de Odontopediatria da FOB-USP para restauração e proservação dos dentes decíduos afetados, assim como também se realizou o acompanhamento periódico a cada 6 meses para controle de cáries nos dentes acometidos pela OR. Paciente foi orientado respeito à técnica de escovação, uso de fio dental, salientando sempre a importância da higienização. Paciente

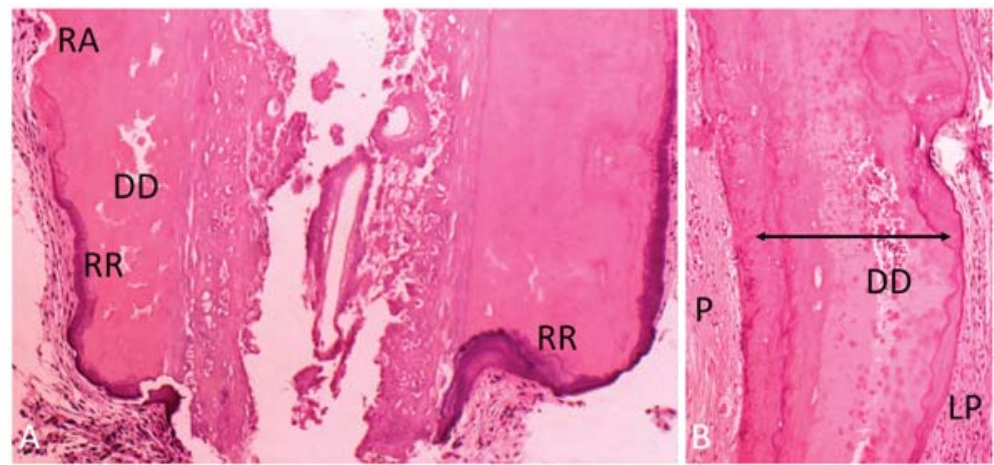

Figura 4. Cortes microscópicos. Em A, nota-se parte da raiz com reabsorção ativa (RA) e reparada (RR) nas superfícies externas. Em B, observa-se a dentina displásica (DD) com áreas amorfas e esféricas basofílicas irregulares, eventuais inclusões celulares, desde a polpa $(\mathrm{P})$ desorganizada até o ligamento periodontal (LP). (HE, $\mathrm{A}=10 \mathrm{X}, \mathrm{B}=25 \mathrm{X})$. 
continua em acompanhamento do crescimento ósseo dos maxilares, e os pais foram alertados da condição dos dentes sucessores permanentes também afetados pela OR e que caso o paciente não tiver os cuidados necessários, pode precisar de uma reabilitação protética multidisciplinar no futuro dessa região da mandíbula.

\section{DISCUSSÃO}

As anomalias de desenvolvimento são abundantes e podem ser subcassificadas em alterações de desenvolvimento, congênitas ou adquiridas, como também podem ser variações no número, forma e padrão de erupção normal dos dentes (13). A OR esta classificada nas alterações de desenvolvimento e subclassificada na morfologia alterada dos dentes.

Nos últimos 5 anos foi realizado um levantamento na literatura dos casos clínicos publicados (tabela 1). As principais características clínicas relatadas são presença de dentes hipomineralizados, dentes com cor marrom, acastanhados ou amarelados, fistulas, tumefação cervicofacial e intrabucal, decíduos parcialmente irrompidos, gengivite, etc (14-21).

A OR pode acometer isoladamente os dentes decíduos quanto os permanentes, assim como afetar ambas dentições. Existem alguns relatos de caso na literatura que descrevem que a OR acomete um dente $(15)$, outros dois dentes $(14,16)$, quatro dentes (14), todos os dentes de um quadrante (18-21), até todos os dentes mandibulares (17), bem como os sucessores permanentes, no caso em que se presente esta condição em dentes decíduos. No presente caso, os dentes acometidos pela OR foi todo o terceiro quadrante de dentes decíduos e os dentes sucessores permanentes.

Os dentes afetados com OR apresentam alteração de forma, ou seja, características como superfície irregular, microdontia, raízes curtas, etc $(14,15,18$ 21). Alguns relatos de casos mostraram a presença de aumento gengival envolta dos dentes diagnosticados com OR $(15,17,20,21)$. Os dentes permanentes afetados podem ter atraso na erupção dentária (14). Neste caso, observou-se além das alterações de cor e forma, a infraoclusão dos dentes e halitose leve, que não foi relatado anteriormente em outros trabalhos. No trabalho de Cavalcante et al., reportaram que o volume da câmara pulpar de um caso com OR na região anterior da mandíbula foi aproximadamente $25 \%$ maior comparado ao dente do lado oposto, essa análise foi feita a partir de imagens de Tomografia computadorizada de feixe cônico com o software ITK-SNAP 3.4.0® (Cognitica, Filadélfia, EUA). Além disso, observou-se que o dente com OR foi de aproximadamente $28 \%$ menor que o dente contralateral correspondente. No mesmo trabalho, observaram nos exames de imagem um padrão de radiopacidade intenso no osso trabecular adjacente à região $\mathrm{OR}$, realizaram uma análise fractal, resultando em um valor de dimensão fractal de 1.171, diferindo do osso não afetado cujo valor foi de 1.309 , o que indica uma microarquitetura óssea alterada na região da OR (21).

O tratamento para dentes com diagnóstico de OR é variável, dependendo da idade e condição clínica encontrada em cada paciente. Pode ser conservador, realizando desde programas preventivos de cárie, que incluiu uso regular de verniz de flúor, selantes de fissuras, entre outras condutas, e já nos casos de dentes com cáries é indicado restaurações com cimento ionômero de vidro e nos casos com lesões periapicais, o mais indicado seria um tratamento mais invasivo, como a exodontia para evitar fistulas ou manifestações mais severas como a tumefação cervicofacial provocada por infecção de origem dentária $(18,20)$. Além disso, para a reabilitação pode ser confeccionado aparelho protético provisório de resina acrílica para preservar a crista alveolar durante o período de crescimento esquelético ou reabilitar temporariamente com mantenedor de espaço removível (14). Nos casos de pacientes com OR, deve-se realizar aconselhamento dietético, instruções de higiene bucal e controles periódicos devido a que os dentes permanentes podem ser afetados e também para acompanhar a erupção dentária $(17,19)$.

\section{CONCLUSÃO}

A OR é mais frequentemente diagnosticado em crianças, assim é importante o atendimento multidisciplinar devido a que pode apresentar complicações, e precisar de uma reabilitação futura na área afetada. O cirurgião-dentista frente à alteração de cor de dentes decíduos pode considerar no diagnóstico diferencial a OR, e os exames 
Tabela 1. Reporte de casos de Odontodisplasia Regional encontrados nos últimos 5 anos da literatura (2014-2018)

\begin{tabular}{|c|c|c|c|c|c|c|c|c|}
\hline Autores/ano & & Sexo & $\begin{array}{l}\text { Idade } \\
\text { (anos) }\end{array}$ & Sintomas/ Evolução & Região acometida & Características clinicas & $\begin{array}{l}\text { Características } \\
\text { radiográficas de dentes } \\
\text { acometidos }\end{array}$ & $\begin{array}{l}\text { Histórico de } \\
\text { trauma, infecção/ } \\
\text { Antecedente } \\
\text { familiar }\end{array}$ \\
\hline Cavalcante et al., 2018 & & M & 08 & $\begin{array}{l}\text { Dor dentária / } \\
\text { Desconhecida }\end{array}$ & Terceiro quadrante & $\begin{array}{l}\text { Aumento gengival, alteração } \\
\text { de forma, hipoplasia }\end{array}$ & $\begin{array}{l}\text { 81, 82, 83, 43, 44, } 45 . \\
\text { 84, } 85 \text { e } 46 \text { com cárie. } \\
\text { Agenesia: } 41,42 \\
\text { Lesão periapical: } 81\end{array}$ & Não / Não \\
\hline Bowden et al., 2018 & & $\mathrm{~F}$ & 03 & $\begin{array}{l}\text { Dor espontânea, } \\
\text { redução de ingesta } \\
\text { oral / } 2 \text { dias }\end{array}$ & $\begin{array}{l}\text { Segundo } \\
\text { quadrante }\end{array}$ & $\begin{array}{l}\text { Tumefação cervicofacial } \\
\text { LE e intrabucal ( } 63 \text { a 26), } \\
\text { fistula (61), hipoplasia, } \\
\text { hipocalcificação,aumento } \\
\text { gengival, alteração de forma, } \\
\text { amarelados }\end{array}$ & $\begin{array}{l}61,62,63,64,65,26 . \\
\text { Com fratura vertical da } \\
\text { coroa: } 63\end{array}$ & $\begin{array}{l}\text { Infecção (fistula 61) } \\
\text { / Não }\end{array}$ \\
\hline Jahanimoghadam et al., 2016 & & $\mathrm{~F}$ & 05 & $\begin{array}{l}\text { Dor no dente } 55 \text { / } 6 \\
\text { meses }\end{array}$ & $\begin{array}{l}\text { Primeiro } \\
\text { quadrante }\end{array}$ & $\begin{array}{l}\text { Fistulas: } 51 \text { e } 52 \text {. Alteração } \\
\text { de forma e cor marrom- } \\
\text { amarelada }\end{array}$ & $\begin{array}{l}\text { Todos os dentes decíduos } \\
\text { e permanentes do primeiro } \\
\text { quadrante }\end{array}$ & $\begin{array}{l}\text { Infecção (fistula } 51 \\
\text { e 52) / Mãe tomava } \\
\text { medicamentos } \\
\text { durante gravidez. }\end{array}$ \\
\hline Prakash et al., 2015 & & $\mathrm{~F}$ & 08 & $\begin{array}{l}\text { Nenhum, com queixa } \\
\text { de alteração de cor } \\
\text { dos dentes }\end{array}$ & Dentes: 55 e 65 & $\begin{array}{l}\text { Alteração de forma de } 55 \text { e } \\
65 \text {, cor marrom-amarelada. } \\
\text { Diagnóstico de NEVIL }\end{array}$ & $\begin{array}{l}55,65 \text { com esmalte } \\
\text { hipoplásico, } \\
\text { hipomineralizado. } \\
\text { Agenesia do } 15\end{array}$ & Não / Não \\
\hline Mathew et al., 2015 & & $\mathrm{~F}$ & 10 & $\begin{array}{l}\text { Dor e edema, } 26 \\
\text { sensível à percussão/ } \\
\text { NR }\end{array}$ & Dente: 26 & $\begin{array}{l}\text { Aumento gengival, } 26 \\
\text { parcialmente irrompido. } \\
\text { Alteração de forma do } 65 \\
\text { (esfoliado faz } 2 \text { anos) e } 26\end{array}$ & $\begin{array}{l}\text { Dentes } 26 \text { com raízes } \\
\text { curtas, ápice aberto e } \\
\text { câmara pulpar aumentada, } \\
\text { com lesão periapical }\end{array}$ & $\begin{array}{l}\text { Lesão periapical no } \\
26 / \text { Não }\end{array}$ \\
\hline Venkatesh Babu et al., 2015 & $\mathrm{M}$ & & 02 & $\begin{array}{l}\text { Nenhum, queixa de } \\
\text { erupção tardia }\end{array}$ & $\begin{array}{l}\text { Todos os } \\
\text { dentes decíduos } \\
\text { mandibulares }\end{array}$ & $\begin{array}{l}\text { Dentes decíduos parcialmente } \\
\text { irrompidos, aumento } \\
\text { gengival, amarelados, } \\
\text { hipoplasia }\end{array}$ & $\begin{array}{l}\text { Todos os dentes da } \\
\text { mandíbula com câmaras } \\
\text { pulpares aumentadas, } \\
\text { nenhum germe } \\
\text { permanente visualizado, } \\
\text { exceto } 36 \text { e } 46\end{array}$ & Não / Não \\
\hline Matsuyama et al., 2014 & $\mathrm{M}$ & & 05 & $\begin{array}{l}\text { Nenhum, queixa que } \\
\text { teve malformação } \\
\text { de dentes anteriores } \\
\text { decíduos }\end{array}$ & $\begin{array}{l}\text { Dentes: } 61,62,63 \\
\text { e } 65 \text { (extraídos); } \\
21,22,23 \text { e } 25\end{array}$ & $\begin{array}{l}\text { Edêntulo na região de } 61,62 \\
\text { e } 63,65 \text { cor amarelada com } \\
\text { superfície irregular, }\end{array}$ & $\begin{array}{l}\text { Dentes } 21,22,23 \text { e } 25 \\
\text { com alteração de forma, } \\
\text { pequenos e hipoplásicos, } \\
\text { raízes curtas }\end{array}$ & Não / Não \\
\hline Matsuyama et al., 2014 & $\mathrm{M}$ & & 06 & $\begin{array}{l}\text { Nenhum, queixa } \\
\text { de malformação de } \\
\text { incisivos superiores } \\
\text { LD }\end{array}$ & $\begin{array}{l}\text { Dentes: } 51 \text { e } 52 \\
\text { (extraídos); } 11 \\
\text { e } 12 .\end{array}$ & $\begin{array}{l}\text { Alteração de forma de } 51 \text { e } \\
52 \text { (restos radiculares) com } \\
\text { hipoplasia }\end{array}$ & $\begin{array}{l}\text { Dentes } 11 \text { e } 12 \text { com } \\
\text { alteração de forma, } \\
\text { hipocalcificados, } \\
\text { pequenos, hipoplásicos }\end{array}$ & Não / Não \\
\hline Neste caso & $\mathrm{M}$ & & 05 & $\begin{array}{l}\text { Nenhum, queixa } \\
\text { de que "dentes não } \\
\text { se desenvolveram / } \\
\text { desconhecida" }\end{array}$ & $\begin{array}{l}\text { Terceiro } \\
\text { quandrante }\end{array}$ & $\begin{array}{l}\text { Alteração de forma e cor, } \\
\text { infraoclusão, aumento } \\
\text { gengival, halitose, } \\
\text { linfonodos submandibulares } \\
\text { aumentados }\end{array}$ & $\begin{array}{l}\text { Dentes } 71 \text { a } 75 \text { e germes } \\
\text { dentários do } 31,32 \text {, } \\
33 \text { e } 34 \text { encontram- } \\
\text { se com alteração de } \\
\text { forma, hipoplásicos } \\
\text { e hipomineralizados. } \\
\text { Dentes } 74 \text { e } 75 \text { com cárie, } \\
\text { apresentam câmaras e } \\
\text { canais pulpares amplos, } \\
\text { raízes curtas. Dente } 75 \\
\text { com rarefação óssea } \\
\text { circunscrita }\end{array}$ & $\begin{array}{l}\text { Não, infecção (fistula } \\
\text { 75) / Não }\end{array}$ \\
\hline
\end{tabular}

F: feminino, M: masculino, LE: lado esquerdo, LD: lado direito, OR: odontodiaplasia regional, NEVIL: nevo epidérmico verrucoso inflamatório linear, NR: Não reportado. 
de imagem são extremamente importantes para confirmar o diagnóstico, devido às caraterísticas da alteração de desenvolvimento hipoplásico clássico dos tecidos dentários, parecendo a dentes fantasmas pela dificuldade de diferenciar o esmalte e a dentina. Os pacientes que apresentem OR precisam estar cientes das suas complicações decorrentes, e assim salientar a importância da higienização e acompanhamento periódico. Nos casos de dentes decíduos, deve-se acompanhar a erupção dos dentes sucessores permanentes devido a que também podem ser atingidos, assim o cirurgião-dentista deve realizar o acompanhamento tanto clínico quanto radiográfico.

\section{Financiamento:}

O presente trabalho foi realizado com apoio da Coordenação de Aperfeiçoamento de Pessoal de Nível Superior - Brasil (CAPES) - Código de Financiamento 001

\section{Autor correspondente:}

Ana Lúcia Alvares Capelozza. e-mail: anacapel@fob.usp.br

\section{REFERÊNCIAS}

1. Hitchin AD. Unerupted deciduous teeth in a youth aged 15 1/2. Br Dent J. 1934; 56(12):631-33.

2. Zegarelli EV, Kutscher AH, Applebaum E. Odontodysplasia. Oral Surg Oral Med Oral Pathol. 1963; 16(2):187-193.

3. Pindborg JJ. Pathology of the dental hard tissues. 3rd edition. Copenhagen: W.B. Saunders Company; 1970. p.120-3.

4. Magalhães AC, Pessan JP, Cunha RF, Delbem AC. Regional odontodysplasia: case report. J Appl Oral Sci. 2007; 15(6):465-69

5. Casati Alvares L, Tavano O. Curso de Radiologia em Odontologia. Anomalias Dentárias e do Complexo Maxilomandibular En: Interpretação radiográfica. 5ta edição. Cidade: Santos; 2009. p. 190-205.

6. Mehta DN, Bailoor D, Patel B. Regional odontodysplasia.J Indian Soc Pedod Prev Dent. 2011; 29(4): 323-26.

7. Ganguly R, Ramesh A. Regional odontodysplasia: a case of progressive tooth development. J Indian Soc Pedod Prev Dent. 2012; 30(2):176-78.

8. Quinderé LB, Cavalcante RB, Nonaka CF, Miguel MC, de Souza LB. Regional odontodysplasia involving three quadrants of the jaws: a case report. Quintessence Int. 2012; 41(1):13-16.

9. Crawford PJ, Aldred MJ. Regional odontodysplasia: a bibliography. J Oral Pathol Med. 1989; 18(5):251-63.
10. Tervonen SA, Stratmann U, Mokrys K, et al. Regional odontodysplasia: a review of the literature and report of four cases. Clin Oral Investig. 2004; 8(2):45-51.

11. Al-Tuwirqi A, Lambie D, Seow WK. Regional odontodysplasia: literature review and report of an unusual case located in the mandible. Pediatr Dent 2014; 36(1):62-7.

12. Neville BW, Damm DD, Allen CM, Bouquot JE. Patologia Oral e Maxilofacial. 3era edição. Rio de Janeiro: Elsevier; 2009. p.111-112.

13. White SC, Pharoah MJ. Radiologia Oral: princípios e interpretação. 7ma Edição. Rio de Janeiro: Elsevier; 2015. p.597-599.

14. Matsuyama J, Tanaka R, Iizawa F. et al.; Clinical and Radiographic Findings and Usefulness of Computed Tomographic Assessment in Two Children with Regional Odontodysplasia. Case Rep Dent. 2014; 2014:764393. DOI: $10.1155 / 2014 / 764393$

15. Mathew A, Dauravu LM, Reddy SN, Kumar KR, Venkataramana V. Ghost teeth: Regional odontodysplasia of maxillary first molar associated with eruption disorders in a 10-year-old girl. J Pharm Bioallied Sci. 2015; 7(2):S800-3.

16. Prakash SMR, Gupta S, Kamarthi N, Goel S. Inflammatory linear verrucous epidermal nevus and regional odontodysplasia: A rare sorority. Indian J Dent. 2015; 6(4):203-6.

17. Venkatesh Babu NSV, Smriti RJ, Pratima DB. Regional odontodysplasia: Report of an unusual case involving mandibular arch. Contemp Clin Dent. 2015; 6(2):237-39.

18. Al-Mullahi AM, Toumba KJ. Regional Odontodysplasia with Generalised Enamel Defect. Case Rep Dent. 2016; 2016:4574673. DOI: $10.1155 / 2016 / 4574673$

19. Jahanimoghadam F, Pishbin L, Rad M. Clinical, Radiographic, and Histologic Evaluation of Regional Odontodysplasia: a Case Report with 5-year Followup. J Dent (Shiraz). 2016; 17(2):159-163.

20. Bowden E, Carroll C, Gill M, Llewelyn R. Cervicofacial infection in a 3-year-old child with regional odontodysplasia: A case report and literature review. J Oral Maxillofac Pathol. 2018; 22(1):117-120.

21. Cavalcante DS, Fonteles CSR, Ribeiro TR. et al.; Mandibular Regional Odontodysplasia in an 8-yearold Boy showing Teeth Disorders, Gubernaculum Tracts, and Altered Bone Fractal Pattern. Int J Clin Pediatr Dent. 2018; 11(2):128-134.

Recibido: 21-04-20

Aceptado: 23-09-20 